ECCOMAS

\section{Proceedia}

COMPDYN 2021

$8^{\text {th }}$ ECCOMAS Thematic Conference on Computational Methods in Structural Dynamics and Earthquake Engineering M. Papadrakakis, M. Fragiadakis (eds.) Streamed from Athens, Greece, 28 - 30 June 2021

\title{
VALIDATION OF NOVEL SEISMIC DESIGN CRITERIA FOR LIGHTWEIGHT STEEL BUILDING IN EUROPE
}

\author{
Sarmad Shakeel $^{1}$, Marica Navarra ${ }^{2}$, and Alessia Campiche ${ }^{2}$ \\ ${ }^{1}$ NUST Institute of Civil Engineering, School of Civil and Environmental Engineering, National Uni- \\ versity of Science and Technology (NUST), H-12, Islamabad, Pakistan \\ e-mail: sshakil@nice.nust.edu.pk \\ ${ }^{2}$ Department for Structures for Engineering and Architecture, University of Naples Federico II, Piaz- \\ zale Techio 80, Naples, Italy \\ marica.navarra@gmail.com, alessia.campich@unina.it
}

\begin{abstract}
Lightweight Steel (LWS) buildings fabricated with cold-formed steel profiles are a viable alternative to traditional reinforced concrete or masonry buildings for low to mid-rise constructions. The current edition of Eurocode 8 does not provide seismic design guidelines for them in Europe. This paper presents a new seismic design criterion for these buildings, which is proposed to be added in the next edition of Eurocode 8. The criteria include design guidelines for lateral force resisting systems that are most common to LWS buildings. These systems include: CFS strap braced walls and CFS shear walls with steel sheets, wood, or gypsum sheathing. A brief overview of these guidelines and the relevant background information is provided in this paper. Then these guidelines are validated with a numerical study on several building archetypes. Archetypes are designed following the proposed seismic design criteria and analyzed under the suite of forty-four earthquake records. Archetypes are analyzed using both nonlinear pushover analysis and incremental dynamic analysis. Based on the analysis results, their collapse probability is gauged to judge the level of protection against seismic hazard provided by the proposed design criteria.
\end{abstract}

Keywords: Eurocode 8, seismic design criteria, lightweight steel structures, lateral force resisting systems, cold-formed steel 


\section{INTRODUCTION}

Lightweight Steel (LWS) buildings are low to mid-rise constructions fabricated with coldformed steel (CFS) frames. In Europe, the use of these buildings is limited in regions with medium-to-high seismic hazard. This is mainly due to the absence of seismic design guidelines for these types of building in European building codes: Eurocodes. In particular, the Eurocode 8 part 1: EN 1998-1 [1] deals with the seismic design of building structures. The current edition of EN 1998-1 was published back in 2004 and it does not provide a specific seismic design criterion for LWS buildings, which can utilize their energy dissipation potential. Therefore, the main crux of this paper is the proposal of the seismic design criterion for the LWS buildings, which could be included in the upcoming second edition of EN 1998-1.

Design rules for LWS buildings are already available in North American Standard for seismic design of cold-formed steel structures: AISI S400 [2] for use in the USA, Canada, and Mexico. Apart from this, no other building code in the world provides seismic design guidelines for LWS buildings, which can utilize their energy dissipation potential. The design rules given by AISI S400 follow the capacity design approach. For all LFRS covered by AISI S400, it defines energy dissipation mechanisms of dissipative components, provides overstrength requirements concerning non-dissipative components and gives a value of response medication factor accounting for system inherent overstrength and ductility. LWS buildings are not explicitly covered by current edition of EN 1998-1 and only LWS buildings braced with strap braced walls could be designed as common Low dissipative steel structures belonging to Ductility class low (DCL) structures made of Class 4 cross-section profiles, for which EN 1998-1 allows a behavior factor of 1.5 to be used in the design.

The main aim of the paper is to enlighten the readers and users of Eurocodes about the background information on the research works [3-4, 13-22, 5, 23-27-6-12] and the reference design standards, already being used in some parts of the world, which formed the basis of proposed seismic design guidelines for LWS buildings. The design guidelines are explained and its validation through a numerical study on several LWS building archetypes is shown. The second edition of EN 1998-1 will provide rules for LWS buildings laterally braced with four different types of LFRS's: CFS strap braced walls (Figure 1); CFS shear walls with steel sheet sheathing (Figure 2), or wood sheathing, or gypsum sheathing.

a:

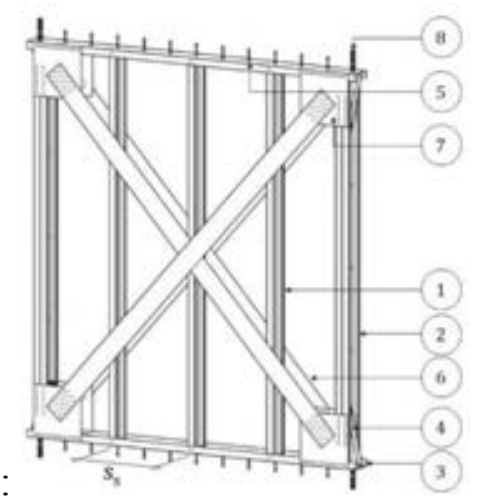

1. stud; 2. chord stud; 3 . track; 4. holddown; 5. shear anchorage; 6. steel strap brace; 7. connection of strap brace; 8 : tension anchorage; ss: stud spacing.

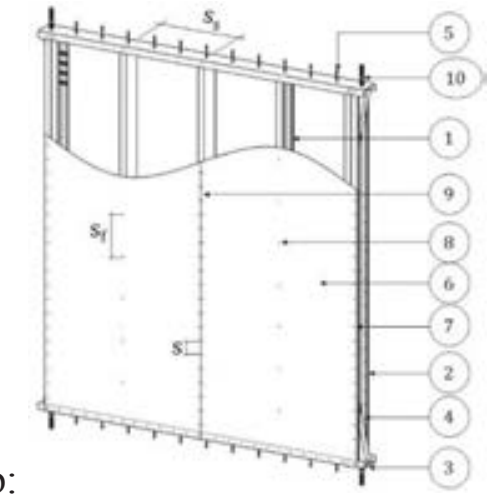

1. stud; 2. chord stud; 3. track; 4. hold-down; 5. shear anchorage; 6. steel sheet or wood or gypsum sheathing; 7 . screw at panel edge; 8: screw in the panel field; 9. sheathing joint; 10. tension anchorage; ss: stud spacing; sf: screw spacing in the panel field; s: screw spacing at panel edge.

Figure 1 a: CFS strap braced wall; b: CFS Shear walls 


\section{DESIGN FRAMEWORK OF 2ND EDITION OF EN 1998-1}

The second editions of Eurocode 8: EN 1998-1 would allow achieving three levels of ductility in building structures equipped with a certain type of LFRS. These levels include:

1. DC1: Low Dissipative structural behavior.

2. DC2: Medium Dissipative structural behavior.

3. DC3: High Dissipative structural behavior.

A structure cannot be designed beyond a certain limit of seismic load in the case of DC1 and DC2 Class structures while in the case of DC3 Class structures, there is no limit on the seismic action. In DC2 and DC3 Class structures, the capability of parts of the LFRS (dissipative components) to resist the seismic actions through plastic behavior in dissipative components is taken into consideration during the design process. To ensure the development of plastic mechanisms and subsequent energy dissipation in the dissipative components, specific design requirements are provided for them. For non-dissipative components of LFRS, design requirements ensure an overstrength in them to safeguard against failure. The overall design process of the second edition of EN 1998-1 would be a capacity design process. The design requirements for the dissipative components of CFS LFRS's belonging to both DC2 and DC3 Class structures would be the same. On the other hand, overstrength requirements for the non-dissipative components would be different for DC2 and DC3 Class structures.

In contrast to the DC2 and DC3 Class structures, the DC1 Class structures would not be required to follow any specific design and overstrength requirements. The design of individual components of DC1 class structure can be carried out according to EN 1993-1-3 [28], and other relevant European building standards [29-30]. Therefore, DC1 class structures would have a limited ductility capacity, and a lower value of behavior factor $(\mathrm{q})$ equal to 1.5 is proposed for them. Meanwhile, in the case of DC2 and DC3 class structures, the ability of structures to dissipate energy through their plastic behavior is accounted for, therefore higher values of $\mathrm{q}$ are proposed for them. The values of the behavior factor for DC2 and DC3 Class structures are derived from the studies [31-32] conducted following the FEMA P695 methodology [33].

Apart from providing special design requirements for DC2 and DC3 Class structures, the second edition of EN 1998-1 will also provide some general rules. These general rules include the limitation on the aspect ratio (height-to-length ratio) of the walls, which is fixed equal to 2.0 for all types of LFRS's. To have a sufficient deformation capacity of connections in the walls, the new version of EN 1998-1 would require the design shear resistance of the screws to be greater than 1.2 times the design bearing resistance of the steel structural member, or the design embedment resistance of wood or gypsum panels (in case of shear walls with panels), or the design net area resistance of the strap brace (in case of strap brace walls). This rule has been derived from the already existing guidelines in EN 1993-1-3 [28] for the shear design of connections made with screws.

\section{DESIGN REQUIREMENTS FOR DISSIPATIVE COMPONENTS}

The second edition of EN 1998-1 would provide specific rules to calculate the design strength of the LFRS in the case of DC2 and DC3 class structures. In addition to these design rules, the code will also provide geometrical and mechanical requirements for the components and parts of the shear walls, which must also be fulfilled to achieve the desired energy dissipation response in the walls. The requirements are defined based on the already existing geometrical and mechanical limitations on the permitted wall configurations given in AISI S400 [2].

For strap braced walls, the yield resistance $\left(\mathrm{N}_{\mathrm{pl}}\right.$, Rd) of the gross cross-section of the strap braces should be greater than the design value of the axial force in the strap brace in the seismic design situation and the design net area resistance $\left(\mathrm{N}_{\mathrm{u}, \mathrm{Rd}}\right)$ of the strap brace. This requirement 
ensures the formation of plastic mechanism in steel straps before the net section failure happens in strap connection to the wall frame. The values of $\mathrm{N}_{\mathrm{pl}, \mathrm{Rd}}$ and $\mathrm{N}_{\mathrm{u}, \mathrm{Rd}}$ can be obtained from other relevant parts of Eurocode 3 [30].

In case of shear walls with steel sheet sheathing, the in-plane lateral resistance $\left(R_{c, R d}\right)$ corresponding to the strength of the sheathing connection within the effective sheathing strip should be greater than the design value of the lateral force acting on the shear wall in the seismic design situation, but it should be less than, the design yielding resistance of the effective sheathing strip $\left(R_{y, R d}\right)$. $R_{c, R d}$ and $R_{y, R d}$ are evaluated based on the effective strip method (ESM) proposed in [31]. ESM was calibrated based on the large amount of steel sheathed shear walls tested in USA and Canada over recent years. In the original proposed ESM [31], $\mathrm{R}_{\mathrm{c}, \mathrm{Rd}}$ is calculated according to Eq. (1), which relies on the formulation of North American specification for the design of CFS structural members AISI S100 [32] for the calculation of single sheathing connection bearing strength $\left(\mathrm{F}_{\mathrm{b}, \mathrm{Rd}}\right)$.

$$
R_{c, R d}=1.33 n F_{b, R d} \cos \left(\operatorname{Arctan}\left(\frac{h}{w}\right)\right)
$$

where $\mathrm{F}_{\mathrm{b}, \mathrm{Rd}}$ is the bearing resistance of the sheathing connection, $\mathrm{n}$ is the number of sheathing connections in the effective with, $h$ is the height of wall and $w$ is the length of wall. AISI S100 provides a different relationships for $\mathrm{F}_{\mathrm{b}, \mathrm{Rd}}$ than the one provided in Eurocode 3 [28]. Eq. (2) and (3) gives the formulations of $F_{b, R d}$ given by AISI S400. If $t_{1} / t \leq 1.0$, then Eq. (2) is used or if $t_{1} / t \geq 2.5$, then Eq. (3) is used else $F_{b, R d}$ can be linearly interpolated between the values obtained from Eq. (2) and (3).

$$
\begin{aligned}
& \mathrm{F}_{\mathrm{b}, \mathrm{Rd}}=\min \left(2\left(\mathrm{t}_{1}^{3} \mathrm{~d}\right)^{\frac{1}{2}} \mathrm{f}_{\mathrm{u}, 1} ; 2.7 \mathrm{tdf}_{\mathrm{u}} ; 2.7 \mathrm{t}_{1} \mathrm{df}_{\mathrm{u}, 1}\right) / \gamma_{M 2} \\
& \mathrm{~F}_{\mathrm{b}, \mathrm{Rd}}=\min \left(2.7 \mathrm{tdf}_{\mathrm{u}} ; 2.7 \mathrm{t}_{1} \mathrm{df}_{\mathrm{u}, 1}\right) / \gamma_{M 2}
\end{aligned}
$$

where $f_{u, 1}$ and $f_{u}$ are the ultimate tensile strength of the framing elements and the sheathing, respectively; $t_{1}$ is the thickness of stud or track; $d$ is the nominal diameter of screws and $\gamma_{\mathrm{M} 2}$ is the partial safety factor equal to 1.25. Contrarily in the European standard for cold-formed steel design (EN1993-1-3 [28]), a different formula is proposed. Authors in their recent study [34] checked the validity of the ESM with $\mathrm{F}_{\mathrm{b}, \mathrm{Rd}}$ evaluated according to equation given by EN 19931-3. The use of the value of $F_{b, R d}$ evaluated from equation by EN 1993-1-3 results in underestimation of the wall strength. Therefore, the second edition of EN 1998-1 would require the strength of sheathing connections $\left(\mathrm{F}_{\mathrm{b}, \mathrm{Rd}}\right)$ to be calculated according to equation (2) and (3), that are taken from AISI S100.

For CFS shear walls with wood or gypsum sheathing, the in-plane lateral resistance $\left(\mathrm{R}_{\mathrm{c}, \mathrm{Rd}}\right)$ corresponding to the strength of the sheathing connection should be greater than the design value of the lateral force acting on the shear wall in the seismic design situation.

\section{OVERSTRENGTH REQUIREMENTS}

To guard the non-dissipative components of the LFRS's against the failure, an overstrength would be provided in them for use in DC2 and DC3 class structures according to the second edition of EN 1998-1.

\subsection{DC2 class structure}

The overstrength requirements for the DC2 Class structures ensure the formation of the desired energy dissipation mechanism in the dissipative components of LFRS through an overstrength in the non-dissipative components. The overstrength factors are applied using Equation (4) on the non-dissipative components of the LFRS of a DC2 Class structure to verify their strength and stability against the most unfavorable combination of the axial force $N_{\mathrm{Ed}}$. 


$$
N_{E d}=N_{E d, G} "+" \Omega N_{E d, E}
$$

where: $N_{\mathrm{Ed}, \mathrm{G}}$, is the axial force in the non-dissipative member due to the non-seismic actions included in the combination of actions for the seismic design situation; and $N_{\mathrm{Ed}, \mathrm{E}}$, is the axial force in the non-dissipative member due to the design seismic action. The overstrength factor for different types of LFRS's is listed in Table 1 along with their behavior factor.

\begin{tabular}{lll}
\hline LFRS & $\mathbf{q}$ & $\mathbf{\Omega}$ \\
\hline Strap braced walls & 2.0 & 1.5 \\
Shear walls with steel sheet sheathing & 2.0 & 1.5 \\
Shear walls with wood sheathing & 2.0 & 1.5 \\
Shear walls with gypsum sheathing & 1.7 & 1.35 \\
\hline
\end{tabular}

Table 1 Behavior and overstrength factors for DC2 Class structures

\subsection{DC3 class structures}

The overstrength requirements for DC3 class structure are different for each type of LFRS in the second edition of EN-1998-1. For strap braced walls, the brittle components listed in Section 2.1 should be designed with an overstrength computed according to (5).

$$
R_{d} \geq F_{E d, G}+\gamma_{r m} \gamma_{s h} R_{f y}
$$

where, $R_{\mathrm{d}}$ is the design resistance of the non-dissipative brittle component; $F_{\mathrm{Ed}, \mathrm{G}}$ is the design action in the component due to the non-seismic actions included in the combination of actions for the seismic design situation; $\gamma_{\mathrm{rm}}$ is the overstrength factor accounting for the variability of the steel yield strength in the dissipative zones, i.e., ratio between the expected (average) and nominal yield strength, and ranges from 1.20 to 1.45 for lower to higher steel grades, $\gamma_{\mathrm{sh}}$ is the overstrength factor accounting for the hardening in the dissipative zones and is equal to $1.1 ; R_{\mathrm{fy}}$ is the plastic resistance of the gross cross-section of the strap braces based on the based on the nominal yield stress of the material as defined in Eurocode 3 [35].

For shear walls with steel sheet sheathing, equation (6) is proposed, which ensures the overstrength in their brittle components.

$$
R_{d} \geq F_{E d, G}+\gamma_{r m} R_{c, R d}
$$

where $\gamma_{\mathrm{rm}}$ is the overstrength factor, i.e., ratio between the expected (average) and design inplane lateral resistance of the shear wall, equal to 1.40 , and $R_{\mathrm{c}, \mathrm{Rd}}$ is the design in-plane lateral resistance of the shear wall evaluated based on sheathing connection strength calculated according to equation (1).

For CFS shear walls with gypsum or wood sheathing, equation (7) is used to provide overstrength in their brittle components.

$$
R_{d} \geq F_{E d, G}+\gamma_{r m} R_{c, k}
$$

where $\gamma_{\mathrm{rm}}$ is the overstrength factor, i.e., ratio between the expected (average) and characteristic in-plane lateral resistance of the shear wall, equal to 1.50 , and $R_{\mathrm{c}, \mathrm{k}}$ is the characteristic inplane lateral resistance of the shear wall. Table 2 summarizes the values of $\gamma_{\mathrm{rm}}$ used for the overstrength of DC3 Class structures along with the values of the behavior factor for different LFRS's.

\begin{tabular}{lll}
\hline LFRS & $\mathbf{q}$ & $\gamma_{\text {rm }}$ \\
\hline Strap braced walls & 2.5 & 1.20 to 1.45 \\
Shear walls with steel sheet sheathing & 2.5 & 1.40 \\
Shear walls with wood sheathing & 2.5 & 1.50 \\
Shear walls with gypsum sheathing & 2.0 & 1.50 \\
\hline
\end{tabular}

Table 2 Behavior and overstrength factors for DC3 Class structures 


\section{VALIDATION OF DESIGN CRITERIA}

To validate the design rules listed in previous sections, proposed for inclusion in the second edition EN1998-1, a numerical study considering several building archetypes was performed. LWS building archetypes braced with all four types of seismic force-resisting systems were designed as both DC2 and DC3 class structures. Nonlinear FE models for the archetypes were developed in OpenSees software [36]. The seismic performance of the models is evaluated following the FEMA P695 methodology [33].

\subsection{Building archetypes}

A total of eight double-storey residential building archetypes designed as DC2 or DC3 class structures and braced with the four types of LFRS's were selected. The archetypes were assumed to be situated on a soil type $\mathrm{C}$ in a medium seismic intensity zone having reference PGA (Peak Ground Acceleration), $\mathrm{ag}, \mathrm{R}$, of $0.2 \mathrm{~g}$, which has a $10 \%$ probability of exceedance in 50 years. The live load due to residential occupancy was $2.0 \mathrm{kN} / \mathrm{m}^{2}$. In addition to permanents loads and live loads, a $1.00 \mathrm{kN} / \mathrm{m}^{2}$ snow load and $0.35 \mathrm{kN} / \mathrm{m}^{2}$ wind load were also considered to be acting.

EN 1993-1-3 [28] was used to design the gravity load resisting elements of the archetypes. Current in practice edition of Eurocode 8: EN 1998-1 [1] was used to define the seismic actions on the buildings. The lateral force method was used to obtain the building design base shear $\left(\mathrm{F}_{\mathrm{b}}\right)$, which is mainly the function of building design response spectrum and mass.

The seismic design process of LWS buildings involves the selection of configurations of strap braced or shear walls, that can be used to resist the lateral actions, evaluating the design strength of the wall configurations, and then eventually the total number of the required walls are obtained by dividing the design base shear with the design strength of a single wall. Table 3 lists the design base shear of the archetypes $\left(F_{b}\right)$, design strength of the walls $\left(R_{d}\right)$, and the number of the walls provided in each planar direction of the archetype.

\begin{tabular}{|c|c|c|c|c|c|c|c|c|c|}
\hline $\begin{array}{l}\text { Archetype } \\
\text { Ductility }\end{array}$ & Wall name & $\mathbf{w} \times \mathbf{h}^{1}$ & $\mathbf{q}$ & Fb & Rd & $\begin{array}{l}\text { No. of walls } \\
\text { required }^{2}\end{array}$ & $\begin{array}{l}\text { No. of walls } \\
\text { provided }\end{array}$ & $\mathbf{C} / \mathbf{D}^{3}$ & $\mathrm{D} / \mathrm{C}^{4}$ \\
\hline & & & {$[-]$} & $\mathbf{k N}$ & $\mathbf{k N}$ & {$[-]$} & {$[-]$} & {$[-]$} & {$[-]$} \\
\hline \multicolumn{10}{|c|}{ Strap braced walls } \\
\hline DC2 & WLD mod & $2.4 \times 2.7$ & 2 & 212.3 & 43.7 & 4.9 & 6 & 1.235 & 0.81 \\
\hline DC3 & WLD & $2.4 \times 2.7$ & 2.5 & 170.8 & 43.7 & 3.9 & 4 & 1.024 & 0.97 \\
\hline \multicolumn{10}{|c|}{ Shear walls with steel sheet sheathing } \\
\hline DC2 & ST1-c mod & $1.22 \times 2.44$ & 2 & 212.3 & 14.6 & 14.6 & 16 & 1.098 & 0.91 \\
\hline DC3 & ST1-c & $1.22 \times 2.44$ & 2.5 & 170.8 & 14.6 & 11.7 & 12 & 1.024 & 0.97 \\
\hline \multicolumn{10}{|c|}{ Shear walls with wood sheathing } \\
\hline DC2 & wall 14 & $2.44 \times 2.74$ & 2 & 212.3 & 34.3 & 6.2 & 8 & 1.291 & 0.77 \\
\hline DC3 & wall 4 & $1.22 \times 2.74$ & 2.5 & 170.8 & 17.1 & 10.0 & 10 & 1.003 & 0.99 \\
\hline \multicolumn{10}{|c|}{ Shear walls with gypsum sheathing } \\
\hline DC2 & $\underset{\bmod }{S \_2400 C}$ & $2.4 \times 2.3$ & 1.7 & 248.9 & 29.2 & 8.5 & 10 & 1.174 & 0.85 \\
\hline DC3 & S_2400C & $2.4 \times 2.3$ & 2 & 212.3 & 29.2 & 7.3 & 8 & 1.101 & 0.90 \\
\hline
\end{tabular}

Table 3 Seismic design details of building archetypes 
The selected configuration for strap braced walls in the DC3 building archetype has been already tested in an Italian research project [32]. On the other hand, no reference test results were found for the wall, which can only meet the criteria of the DC2 ductility class. Therefore, it was decided to downgrade the DC3 walls in a way that it would become DC2. For this purpose, the chord studs and the hold-down devices have been modified. In this way, the new wall named as WDL mod does not satisfy the design criteria required for the DC3 ductility class but guarantees the fulfillment of the criteria for the DC2.

In the case of steel sheathed shear walls, the selected wall configuration belonging to the DC3 class has already been tested at McGill University in Canada [37] and was named as ST1 -c in the referenced research. On the other hand, DC2 wall configuration is obtained for steel sheathed shear walls similarly to strap braced walls. Likewise, gypsum sheathed shear wall configuration to be used in a DC3 class building is selected from the series of tests carried out at the University of Naples Federico II, Italy within the ELISSA project [32]. The DC3 wall selected from the referenced research was named S_2400C. While DC2 wall configuration is obtained by modifying the chord studs of the DC3 wall configuration in the case of gypsum sheathed shear walls. The wood sheathed shear wall configuration to be used in a DC3 and DC2 class building archetypes were selected from the series of tests carried out in the USA within the CFS NEES project [38]. The tested wall configuration 14 and 4 in the reference research are used as DC2 and DC3 class walls, respectively.

\subsection{Numerical modeling and analysis}

A three-dimensional numerical model was developed for each archetype in OpenSees software [36]. The nonlinear behavior of building archetypes was represented in the lateral load resisting walls. Thus, the simulation of seismic response of the walls is the single most significant consideration in the modeling of LWS building analyzed under the seismic design situation.

A simplified diagonal truss model was used to simulate the in-plane force-displacement hysteretic response of the walls. More detail on the modeling of walls can be found in [32]. Pinching 4 material [39] is used for the diagonal truss elements. The values of pinching 4 material properties are selected from the studies in the literature [32], in which numerical models of selected wall configurations have been developed.

The development of wall models was followed by the development of 3D building models for the archetypes. The model included only the main structural elements: LFRS walls, gravity load-bearing studs, floor representations, and a P-delta frame. The gravity load resisting studs are modeled as the truss elements. The floor was modeled using the rigid elastic beam-column elements. To capture the lateral displacement arising from the P-delta effect, a rigid frame made of axially rigid elastic beam-column elements with low flexure stiffness having a co-rotational coordinate transformation is connected to the building in the direction of seismic action. Gravity load is applied to the P-delta columns at floor levels. More information on the modeling of CFS archetypes is given in [32]. Moreover, a 2\% damping ratio defined based on the Rayleigh damping model is also used in dynamic analysis. These values of damping ratio reflect the values measured during the shake-table tests [32] on LWS building specimens.

\subsection{Analysis, results, and discussion}

To investigate the building performance, pushover analysis and incremental dynamic analysis were performed on the archetypes. The analysis was performed following the framework of the FEMA P695 methodology [33]. More details about the FEMA P695 approach can be found in [32]. Figure 2 show the capacity curves of all archetypes, in which the model base 
shear $\left(\mathrm{V}_{\mathrm{b}}\right)$ was normalized by the design base shear $\left(\mathrm{F}_{\mathrm{b}}\right)$ and the design overstrength $(\mathrm{C} / \mathrm{D}$ ratio), and the top displacement $(\Delta)$ was normalized by building height $(\mathrm{H})$.

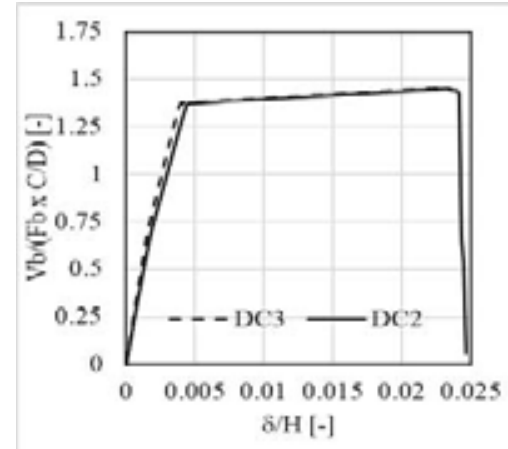

(a)

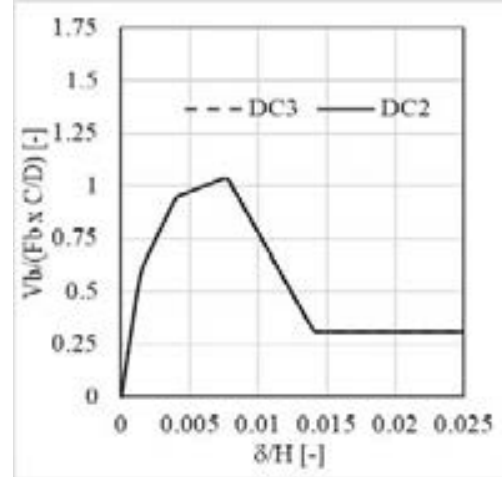

(c)

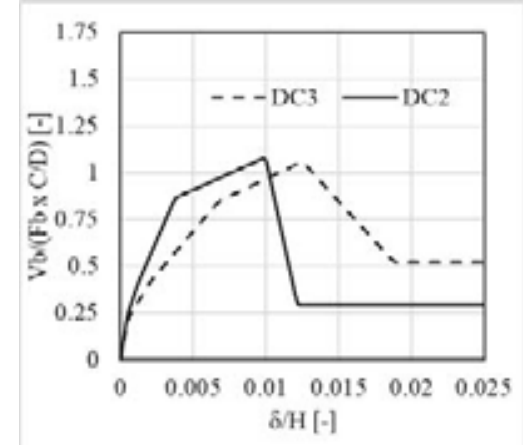

(b)

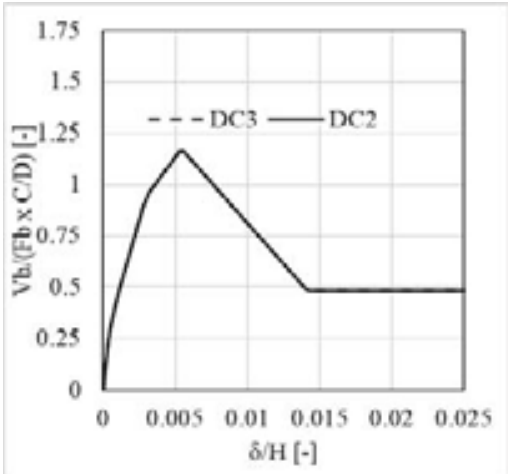

(d)

Figure 2: Pushover curves building archetype models braced with: a) CFS strap braced walls; b) CFS shear walls with wood sheathing; c) CFS shear walls with steel sheathing; d) CFS shear walls with gypsum sheathing.

The pushover curves shown in Figure 3 do not highlight any differences among DC2 and DC3 archetypes in terms of building peak strengths, while small differences were observed in the case of building ductility. During the pushover analysis, no brittle failure mechanism was observed. All the archetypes depicted a failure (inter-storey drifts accumulation) at a particular storey.

To better interpret the results, Incremental Dynamic Analysis (IDA) of all archetypes was performed. The analysis was performed using pair of 22 earthquake records provided by FEMA P695 [33]. The collapse performance of archetypes was gauged using Collapse Margin Ratio (CMR). CMR is defined as the ratio between median collapse intensity $\left(\mathrm{S}_{\mathrm{CT}}\right)$ to the maximum considered earthquake intensity $\left(\mathrm{S}_{\mathrm{MT}}\right)$. $\mathrm{S}_{\mathrm{CT}}$ is defined as the intensity at which half of the ground motions in the record set used during the IDA cause collapse of an archetype model. The archetype collapse was represented by the exceedance of the threshold value of an inter-storey drift ratio. The threshold value of inter-storey drift ratio was the level of the drift until which the individual units of lateral load resisting walls did not experience collapse during the tests [32-37-38]. A value of 5\%,2\%, and 4\% inter-storey drift level was used for archetypes with CFS strap braced, steel sheathed shear, and wood or gypsum sheathed shear wall, respectively.

During IDA, all 44 records (22 records x 2 orthogonal directions) were applied separately to the archetype models in both planar directions. Records were applied in an increment of $20 \%$ in their intensity. IDA started with all the earthquake records have an intensity of $20 \%$ (Scaling factor $=0.2$ ) and was continued up to an intensity of $300 \%$ or $600 \%$ (Scaling factor $=6.0$ ) with increments of $20 \%$, until a failure is not observed. The Scaling factor of 1.0 represents a design 
earthquake (DE) level because the median of all the records was matched with the building design response spectrum as explained earlier. The scaling factor of 1.5 can be considered as MCE (Maximum Considered Earthquake) intensity earthquake. This is due to the fact that the MCE is 1.5 times the DE [40]. Figure 3 shows the results of IDA results for the DC2 Class building archetype braced with CFS steel sheathed shear wall.

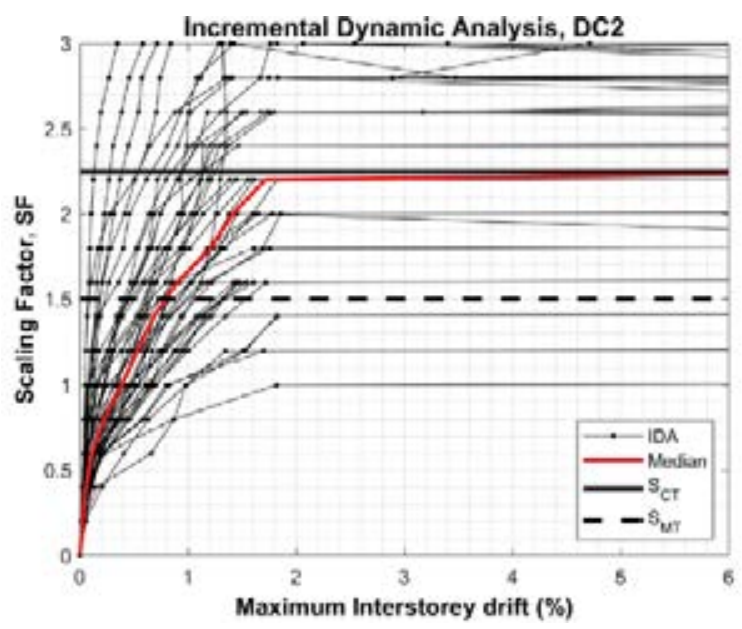

Figure 3: IDA curves for DC2 class building archetype braced with CFS steel sheathed shear wall.

The CMR obtained from IDA is multiplied with the spectral shape factor (SSF) to obtain Adjusted Collapse Margin Ration (ACMR). SSF is provided in the FEMA P695 document [33] as a function of period-based ductility $\left(\mu_{T}\right)$, numerical fundamental vibration period $\left(\mathrm{T}_{1}\right)$ and seismic design category of an archetype [41]. FEMA P695 methodology also outlines a performance evaluation process for the archetypes. In particular, it outlines two performance goals: the average value of ACMR, ACMR avg, for each performance group should be greater than $\mathrm{ACMR}_{10 \%}$, and the individual values of the $\mathrm{ACMR}_{\mathrm{i}}$, for each archetype should be greater than $\mathrm{ACMR}_{20 \%}$. ACMR $10 \%$ and $\mathrm{ACMR}_{20 \%}$ are values of acceptable collapse probability, taken as $10 \%$ and 20\%, respectively, and are given in Table 7-3 of FEMA P695., which lists them as a func-

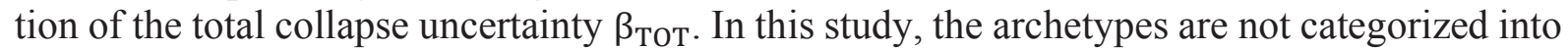
performance groups due to different lateral force resisting systems, therefore the performance against the second goal $\mathrm{ACMR}_{20 \%}$ is only measured.

$\beta_{T O T}$ merges various sources of uncertainty including record to record uncertainty $\left(\beta_{R T R}\right)$, design requirements uncertainty $\left(\beta_{D R}\right)$, test data uncertainty $\left(\beta_{T D}\right)$; and modeling uncertainty $\left(\beta_{M D L}\right)$ using Equation (8).

$$
\beta_{T O T}=\sqrt{\beta_{R T R}^{2}+\beta_{D R}^{2}+\beta_{T D}^{2}+\beta_{M D L}^{2}}
$$

Record to record uncertainty $\left(\beta_{R T R}\right)$ represents the variability in archetypes response model due to the application of various ground motion records, that could have different dynamic characteristics and frequency content. $\beta_{R T R}$ is computed using Equation (9).

$$
\beta_{R T R}=0.1+0.1 \cdot \mu_{T} \text {, with } \beta_{R T R}>0.2 \text { and } \beta_{R T R} \leq 0.4
$$

All of the archetypes had $\beta_{R T R}$ of 0.40 . The rest of the parameters in Equation (11) are qualitative indicators provided by FEMA P695 [33] on the basis of the following scale: (a) Superior, $\beta=0.10$; (b) Good, $\beta=0.20$; (c) Fair, $\beta=0.35$; and (d) Poor, $\beta=0.50$. The design process used in this study ensures the formation of ductile mechanism in the walls, while protecting against brittle failure mechanisms happening in wall components. The design method is also able to predict the design strength of the shear wall in a close match to the test results. Therefore, the design requirements used to design the archetypes are rated as "Good" $\left(\beta_{D R}=0.2\right)$. In authors opinion, the rating can only be excellent, if the seismic design guidelines for LFRS are 
already given in building standards. The available experimental data on LFRS performance is rated as "Superior" $\left(\beta_{T D}=0.1\right)$ for CFS shear walls, because different wall components and walls themselves have been tested, [38] and the seismic performance of the building with LFRS has also been investigated via shake-table tests [42]. For strap braced walls, a rating of "Good" $\left(\beta_{T D}=0.2\right)$ was utilized because there was no shake table data available on their performance. For DC2 building archetypes braced with the walls, which were obtained by modifying respective DC3 walls, rating of test data was taken as poor $\left(\beta_{T D}=0.5\right)$ due to unavailability of test results. Modelling of building archetypes was rated as "Good" $\left(\beta_{M D L}=0.2\right)$ due to their ability to simulate brittle failure mechanisms and post peak deterioration of shear strength. Table 5 shows the performance evaluation results of all archetypes.

\begin{tabular}{|c|c|c|c|c|c|c|c|c|c|c|}
\hline Archetype & $\underset{(\mathbf{s e c})}{T}$ & $\mu_{T}$ & $\mathbf{S}_{\mathrm{CT}}$ & $\mathbf{S}_{\mathrm{MT}}$ & SSF & $\beta_{T O T}$ & CMR & ACMR & $\underset{20 \%}{\mathbf{A C M R}}$ & $\begin{array}{c}\text { ACMR / } \\
\text { ACMR } \\
20 \%\end{array}$ \\
\hline DC2 & 0.30 & 13.0 & 5.40 & 1.50 & 1.14 & 0.70 & 3.60 & 4.10 & 1.80 & 2.28 \\
\hline braced DC3 & 0.35 & 13.6 & 4.20 & 1.50 & 1.14 & 0.50 & 2.80 & 3.19 & 1.56 & 2.04 \\
\hline DC2 & 0.28 & 8.6 & 2.40 & 1.50 & 1.14 & 0.70 & 1.60 & 1.82 & 1.80 & 1.01 \\
\hline $\begin{array}{l}\text { Steel } \\
\text { Sheathed DC3 }\end{array}$ & 0.31 & 9.9 & 1.80 & 1.50 & 1.14 & 0.50 & 1.20 & 1.37 & 1.52 & 0.90 \\
\hline Wood DC2 & 0.33 & 6.0 & 2.80 & 1.50 & 1.12 & 0.50 & 1.87 & 2.09 & 1.52 & 1.38 \\
\hline Sheathed DC3 & 0.48 & 6.4 & 2.20 & 1.50 & 1.12 & 0.50 & 1.47 & 1.65 & 1.52 & 1.09 \\
\hline DC2 & 0.29 & 5.1 & 2.60 & 1.50 & 1.10 & 0.70 & 1.73 & 1.92 & 1.80 & 1.07 \\
\hline $\begin{array}{l}\text { Gypsum } \\
\text { Sheathed DC3 }\end{array}$ & 0.30 & 5.9 & 2.60 & 1.50 & 1.11 & 0.50 & 1.73 & 1.94 & 1.52 & 1.28 \\
\hline
\end{tabular}

Table 4 Performance evaluation of building archetypes based on IDA results.

From the results shown in Table 4, its evident that the proposed design guidelines provide a significant margin of safety (CMR) against collapse. All the archetypes have also ACMR greater than $\mathrm{ACMR}_{20}$ except in the case of the DC3 archetype with CFS steel sheathed shear wall.

\section{CONCLUSIONS}

This paper presents the seismic design criteria for LWS buildings. The design criteria cover four different types of LFRS's: CFS strap braced walls, CFS shear walls with steel sheet or wood or gypsum sheathing, which can be used to achieve three levels of ductility classes in LWS building. Special capacity design rules and limitations on the geometrical and mechanical properties are required to be followed for DC2 and DC3 Class structures, while DC1 Class structures require no specific capacity design rules and limitations. Different values of the behavior factors are also proposed for DC2 and DC3 Class structures. Overstrength rules will be provided separately for DC2 and DC3 class structures to safeguard against the brittle failure mechanism in the non-dissipative components. Furthermore, formulations to predict the design strength of the wall would also be provided.

To validate the proposed design criteria, a numerical study was performed considering several building archetypes. Archetypes were designed following the proposed design criteria and modeled in OpenSees. Pushover analysis on archetypes indicated the redundancy of models against the brittle failure mechanism as they were not observed. Through incremental dynamic analysis, the collapse performance of archetypes was evaluated. All of the archetypes passed the FEMA P695 performance evaluation criteria with a good margin except one, in which the performance goal was not met by the close margin. To conclude, based on the numerical results, it can be asserted that the design criteria allow guaranteeing wide margins of safety against collapse and the desired hierarchy of resistances in the LFRS's. 


\section{REFERENCES}

[1]. CEN, EN 1998-1 Eurocode 8: Design of Structures for earthquake resistance-Part 1: General rules, seismic actions and rules for buildings (Brussels: European Committee for Standardization, 2004).

[2]. AISI, S400-15 North American Standard for Seismic Design of Cold formed Steel Structural Systems (American Iron and Steel Institute (AISI), 2015).

[3]. Fiorino, L., Pali, T., and Landolfo, R., Out-of-plane seismic design by testing of nonstructural lightweight steel drywall partition walls. Thin-Walled Structures, 130, 213 230, 2018.

[4]. Fiorino, L., Bucciero, B., and Landolfo, R., Shake table tests of three storey coldformed steel structures with strap-braced walls. Bulletin of Earthquake Engineering, 2019.

[5]. Fiorino, L., Macillo, V., and Landolfo, R., Experimental characterization of quick mechanical connecting systems for cold-formed steel structures. Advances in Structural Engineering, 20, 1098-1110, 2017.

[6]. Fiorino, L., Iuorio, O., Macillo, V., Terracciano, M. T., Pali, T., and Landolfo, R., Seismic Design Method for CFS Diagonal Strap-Braced Stud Walls: Experimental Validation. Journal of Structural Engineering, 142, 04015154, 2016.

[7]. Iuorio, O., Fiorino, L., and Landolfo, R., Testing CFS structures: The new school BFS in Naples. Thin-Walled Structures, 84, 275-288, 2014.

[8]. Fiorino, L., Iuorio, O., and Landolfo, L., A Specific Procedure for the Seismic Design of Cold-Formed Steel Housing. Proc. 5th Int. Conf. Adv. Steel Struct. (ICASS 2007) (Singapore, 2007), pp. 298-305.

[9]. Fiorino, L., Iuorio, O., MacIllo, V., and Landolfo, R., Performance-based design of sheathed CFS buildings in seismic area. Thin-Walled Structures, 61, 248-257, 2012.

[10]. Fiorino, L., Iuorio, O., and Landolfo, R., Seismic analysis of sheathing-braced coldformed steel structures. Engineering Structures, 34, 538-547, 2012.

[11]. Fiorino, L., Iuorio, O., and Landolfo, R., Sheathed cold-formed steel housing: A seismic design procedure. Thin-Walled Structures, 47, 919-930, 2009.

[12]. Tartaglia, R., D'Aniello, M., and Zimbru, M., Experimental and numerical study on the T-Stub behaviour with preloaded bolts under large deformations. Structures, 27, $2137-$ 2155, 2020.

[13]. Tartaglia, R., D’Aniello, M., Andreini, M., and La Mendola, S., The Performance of Preloaded Bolts in Seismically Prequalified Steel Joints in a Fire Scenario. Materials, 13, 5079, 2020.

[14]. Tartaglia, R., D'Aniello, M., and Landolfo, R., Numerical Simulations to Predict the Seismic Performance of a 2-Story Steel Moment-Resisting Frame. Materials, 13, 4831, 2020.

[15]. Tartaglia, R. and D'Aniello, M., Influence of Transvserse Beams On the Ultimate Behaviour of Seismic Resistant Partial Strength Beam-To-Colummn Joints. Ingegneria Sismica , 37, 50-65, 2020.

[16]. Mario D'Aniello, Tartaglia, R., and Cassiano, D., Experimental investigation of the 
inelastic tensile behaviour of non-preloadable grade 8.8 bolts. Ingegneria Sismica, 37, 92-109, 2020.

[17]. Tartaglia, R., D’Aniello, M., and Rassati, G. A., Proposal of AISC-compliant seismic design criteria for ductile partially-restrained end-plate bolted joints. Journal of Constructional Steel Research, 159, 364-383, 2019.

[18]. Costanzo, S., Tartaglia, R., Di Lorenzo, G., and De Martino, A., Seismic Behaviour of EC8-Compliant Moment Resisting and Concentrically Braced Frames. Buildings, 9, 196, 2019.

[19]. Tartaglia, R. and D'Aniello, M., Nonlinear Performance of Extended Stiffened End Plate Bolted Beam-to-column Joints Subjected to Column Removal. The Open Civil Engineering Journal, 11, 369-383, 2017.

[20]. Tartaglia, R., D'Aniello, M., and De Martino, A., Ultimate Performance of External End-plate Bolted Joints Under Column Loss Scenario Accounting for the Influence of the Transverse Beam. The Open Construction and Building Technology Journal, 12, 132-139, 2018.

[21]. Tartaglia, R., D’Aniello, M., Gianmaria, D. L., and Attilio De Martino, D. M., Influence of EC8 rules on P-Delta effects on the design and response of steel MRF. Ingegneria Sismica: International Journal of Earthquake Engineering, 13, 104-120, 2018.

[22]. Tartaglia, R., D’Aniello, M., Rassati, G. A., Swanson, J. A., and Landolfo, R., Full strength extended stiffened end-plate joints: AISC vs recent European design criteria. Engineering Structures, 159, 155-171, 2018.

[23]. Montuori, R., Nastri, E., Piluso, V., Streppone, S., D’Aniello, M., Zimbru, M., and Landolfo, R., Comparison Between Different Design Strategies For Freedam Frames: Push-Overs and Ida Analyses. The Open Construction and Building Technology Journal, 12, 140-153, 2018.

[24]. Castaldo, P., Nastri, E., and Piluso, V., Ultimate behaviour of RHS temper T6 aluminium alloy beams subjected to non-uniform bending: Parametric analysis. ThinWalled Structures, 115, 129-141, 2017.

[25]. Castaldo, P., Nastri, E., and Piluso, V., FEM simulations and rotation capacity evaluation for RHS temper T4 aluminium alloy beams. Composites Part B: Engineering, 2017.

[26]. Montuori, R., Nastri, E., and Piluso, V., Modelling of floor joists contribution to the lateral stiffness of RC buildings designed for gravity loads. Engineering Structures, 121, 85-96, 2016.

[27]. Nastri, E., Vergato, M., and Latour, M., Performance evaluation of a seismic retrofitted R.C. precast industrial building. Earthquakes and Structures, 12, 13-21, 2017.

[28]. CEN, EN 1993-1-3 Eurocode 3: Design of steel structures-Part 1-3: General rulesSupplementary rules for cold-formed members and sheeting (Brussels: European Committee for Standardization, 2006).

[29]. CEN, EN 1994-1-1 Eurocode 4: Design of composite steel and concrete structures Part 1-1: General rules and rules for buildings (Brussels: European Committee for Standardization, 2004). 
[30]. CEN, EN 1995-1-1 Eurocode 5: Design of timber structures Part 1-1: general Common rules and rules for buildings (Brussels: European Committee for Standardization, 2005).

[31]. Shamim, I. and Rogers, C. A., Numerical evaluation: AISI S400 steel-sheathed CFS framed shear wall seismic design method. Thin-Walled Structures, 95, 48-59, 2015.

[32]. Landolfo, R., Lightweight steel framed systems in seismic areas: Current achievements and future challenges. Thin-Walled Structures, 140, 114-131, 2019.

[33]. FEMA, FEMA P695: Quantification of Building Seismic Performance Factors (Washigton, DC, USA, 2009).

[34]. Campiche, A., Shakeel, S., Fiorino, L., and Landolfo, R., Seismic design criteria for CFS steel-sheathed shear walls. Stab. Ductility Steel Struct. - Proc. Int. Colloq. Stab. Ductility Steel Struct. 2019 (2019).

[35]. CEN, EN 1993-1-1 Eurocode 3: Design of steel structures-Part 1-1: General rules and rules for buildings (Brussels: European Committee for Standardization, 2005).

[36]. Mazzoni, S., McKenna, F., Scott, M. H., and Fenves, G. L., OpenSees. 2009.

[37]. Shamim, I., DaBreo, J., and Rogers, C. A., Dynamic Testing of Single- and DoubleStory Steel-Sheathed Cold-Formed Steel-Framed Shear Walls. Journal of Structural Engineering, 139, 807-817, 2013.

[38]. Liu, P., Peterman, K. D., and Schafer, B. W., Impact of construction details on OSBsheathed cold-formed steel framed shear walls. Journal of Constructional Steel Research, 101, 114-123, 2014.

[39]. Mazzoni, S., McKenna, F., Scott, M. H., and Fenves, G. L., Open System for Earthquake Engineering (OpenSees). 2009.

[40]. Leyendecker, E. V., Hunt, R. J., Frankel, A. D., and Rukstales, K. S., Development of Maximum Considered Earthquake Ground Motion Maps. Earthquake Spectra, 16, $21-$ 40, 2000.

[41]. SEI/ASCE, ASCE 7-16 Minimim Design Loads for Buildings and Other Structures (Reston, Virginia: American Society of Civil Engineers, 2016).

[42]. Peterman, K. D., Stehman, M. J. J., Madsen, R. L., Buonopane, S. G., Nakata, N., and Schafer, B. W., Experimental Seismic Response of a Full-Scale Cold-Formed SteelFramed Building. II: Subsystem-Level Response. Journal of Structural Engineering, 142, 04016128, 2016. 